\title{
The Critical Period Hypothesis Revisited: The Implications for Current Foreign Language Teaching to Young Learners
}

\author{
Esim Gürsoy \\ Uludag University, Bursa, Turkey \\ Email: esimgursoy@yahoo.com
}

\begin{abstract}
Teaching foreign languages to young learners is gaining popularity all over the world and as a result the age for learning a second/foreign language is being reduced in many countries. However, the outcomes of early language teaching haven't been thoroughly investigated and the question related to why we are teaching English at younger ages is not answered adequately. The SLA research has investigated the issue of age as an outcome of $L 1$ acquisition research. The studies related to age and the 'Critical Period Hypothesis' (CPH) were mostly conducted in the second language environments and neglected the foreign language contexts. Moreover, the results of such studies, where adults versus children; and younger children versus older children are compared, have conflicting findings. Thus, the study aims to reconsider the 'Critical Period Hypothesis' by discussing significant considerations in the literature, such as neurolinguistic, cognitive and affective arguments and studies comparing children with adults. It also aims to shed some light on current foreign language teaching practices. In addition, the implications of the CPH to teaching English to young learners will be discussed.
\end{abstract}

Index Terms - the critical period hypothesis, $\mathrm{CPH}$, young learners, foreign language learning

\section{INTRODUCTION}

Recently, the starting age for learning a second/foreign language (SL/FL) has been reduced in many countries in Europe and Asia. The efforts for learning FLs are not only a result of globalization but also the result of "younger the better" philosophy. Learning languages become a societal need to have better jobs, wider communication opportunities and higher social standards. The issue of age for learning languages has been the scope of linguistic and FL education studies for a long time. The initial studies were triggered by the Critical Period Hypothesis $(\mathrm{CPH})$. Thus, the current study aims to revisit the CPH with extensive literature review to shed some light on the current language teaching practices.

\section{BACKGROUND}

\section{A. Neurolinguistic Arguments}

In the previous second language research, learners' inability, beyond a certain age, to learn the second language's certain aspects is considered as a biological and developmental phenomenon, which has been argued within the scope of the critical period hypothesis (CPH) (Brown, 1980). Competence, in behavioral domains, is believed to increase gradually as the person develops. However, in domains such as SL/FL language development, it has been argued that this continuous increase of competence reaches a peak point and then starts to decline after this period (Johnson \& Newport, 1989).

According to critical period hypothesis, which was first put forward for the learning of the mother tongue, language acquisition process must be completed before puberty, for it is suggested that language develop fully until then. Although critical period was suggested for first language acquisition, the claim that brain reaches its adult values until puberty and that there will be a loss of brain plasticity and its reorganizational capacities, made researchers undertake studies of second language learning over age. If there is a critical period, then it must have a different characteristic when it is applied to second language learning (Johnson \& Newport, 1989). CPH has not been interpreted adequately in some cases, where it was assumed that by puberty you are "over the hill" to learn a second language successfully (Brown, 1993). This interpretation constitutes the strong version of the hypothesis. In other words, what CPH says according to this version is that natural and complete acquisition of a language can occur only between the ages two and puberty, and also that children and adults acquire the language differently (Krashen, Sferlazza, Feldman, and Fathman, 1976). 
In contrast to these claims, Krashen (1973) suggests that, lateralization of the brain is complete before puberty, and therefore it is "not a barrier to accent-free second language learning by adults" (p. 63). He argues that lateralization process develops during first language acquisition, as early as age five.

Krashen (1973) supports this idea by looking at the "reports of psychological testing of children with unilateral brain damage" (p. 65). According to the results of the previous studies he examined, unilateral brain damage causes same results both in children and adults; "left lesions impair performance on verbal tests and do not affect performance on spatial and configurational tests, while right sided lesions impair performance on spatial and configurational tests and do not affect verbal scores" (p. 65).

Krashen (1973) also looked at the results of dichotic listening, that is, presenting subjects "with competing simultaneous auditory stimuli, one to each ear. In right handed subjects the right ear generally excels for verbal material, reflecting left hemisphere specialization. The left ear excels for certain non-verbal stimuli, indicating right hemisphere dominance" (p. 66). CPH, that suggests lateralization after puberty, claims that, in dichotic listening the superiority of the right ear would increase during childhood, and it would reflect the growing dominance of the left hemisphere. On the contrary, "lateralization-by-five hypothesis" claims that the superiority degree would not change after the age five. Krashen (1973), supports this idea with his study where he tested children between the ages four and nine, and could neither find a significant change in the degree of lateralization, nor a right ear advantage.

In the light of these explanations it can be assumed that, the development of lateralization is completed far before puberty. Therefore, it is possible to learn a second language after puberty. However, this time language learning might not be rapid or efficient as the acquisition of the native language. In addition to this, completion of lateralization does not construct a barrier to the language learner (Krashen, 1973).

\section{B. Cognitive and Affective Arguments}

Brown (1980), brings out an affective component to the CPH, which he calls "the optimal distance model". Some researchers have based their explanations on the optimal stage, on the lateralization of the brain functions, and some others supported their hypothesis by cognitive and affective arguments. It is then, the CPH was extended to second language learning. Most of us have observed that children can learn second languages more easily than adults. And most of us assumed that adults are rather inefficient and unsuccessful when compared to children (Brown, 1980).

As a result of the research on this area cognitive and affective arguments found to be more convincing than physiological, brain-related arguments. However, both of these arguments agreed that the ease or difficulty of learning a language, either first or second, is age-related. Brown (1980) argues that, if second language acquisition (SLA) is occurring within the second language culture it might be possible to explain $\mathrm{CPH}$ by including socio-cultural factors. He claims that such factors, no matter the person's age, go through acculturation. If second language learning is happening in the second language culture, it is very much related with culture learning. Brown (1980) further claims that "The interaction of language and culture produces a syndrome which gives rise to a certain stage during which language learning achieves an optimal level. At that critical stage, adults and children, have an optimal chance to become fluent in the second language." (p. 158) According to Brown (1980), there are four aspects of the optimal distance model:

1) Acculturation: He claims that there are four stages of the acculturation process that people face while assimilating in a new culture:

a) Period of excitement and euphoria: this stage is a result of the new environment.

b) Culture Shock: This stage occurs when the person becomes aware of the cultural differences and sees those differences as a threat to his self and security. During this stage the person looks for people from his culture to rely on. The result of this stage may be the feelings of estrangement, frustration, homesickness, ... etc.

c) Gradual Recovery: In this stage the person solves some of his problems about the new culture, and he becomes more empathetic, and starts to appreciate the differences between his culture and the target language culture.

d) Assimilation or Adaptation: This is a result of near or full recovery. The person starts to build in self-confidence in the new culture.

2) Anomie: As a result of learning a second language and being exposed to, or living in, the second language culture people may have feelings, such as social uncertainty or dissatisfaction.

3) Social Distance: "Social distance refers to the cognitive and affective proximity of two cultures which come into contact with an individual." (p. 158) Distance, here, represents the differences between the two cultures.

4) Perceived Social Distance: Each person perceives the same cultural environment differently. Their perception is through the "filters of their own world" (Brown, 1980, p. 160), then, no matter how biased their opinion may be, they act upon their perception.

Brown (1980) claims that, the beginning of the third stage in acculturation process, is the point when persons gain skillful fluency in second language. Adults' failure in synchronizing linguistic and cultural development may result with a failure in learning a second language in the second language culture. Since children do not have a culture bound view, they do not have perspective filters like adults do, and as a result they can pass through the acculturation process quickly, and consequently learn the language more quickly. 
The limitation of the optimal distance model is that, it is applicable to only SL learning in the target language culture. According to optimal distance model, the adults experience difficulty in SL learning because acculturation and language development is inefficiently synchronized (Brown, 1980).

\section{Younger Children versus Older Children}

"Second language learning primarily involves the acquisition of a new set of realization rules by means of which the new language expresses underlying relations and modes of the cognitive organization of a universal type" (Richards, 1975 , p. 126). Studies have shown that the rule-system of the language learner is not a result of imitation. As it is understood from the error analysis, the learner recreates the system of the language for himself by the help of universal learning strategies. One of the universal principles of child language, and an adult second language learner is their tendency towards the simplification of the rules. That is, by applying them into expanded areas, and by dropping rules where there is a limited applicability (Richards, 1975).

Errors made by children learning English as their second language, are developmental, not interference errors as it was thought. In this sense their errors are similar to the errors of children who learn English as their mother tongue (Bailey, Madden, and Krashen, 1974).

Adults' errors, on the other hand, are mostly the same with the learners of different native languages and considered false hypotheses about the second language (Bailey, Madden, and Krashen, 1974). Bailey, Madden, and Krashen (1974) argued that adult target language learning has natural sequence of acquisition. Adults were compared with older children, whose ages are between five and eight, in respect to their cognitive maturity. Consequently, the result of their study showed that adults use similar strategies with children, when learning a second language. Adults having different native languages made similar mistakes, which proved that errors made while learning second languages are not always the result of interference from the mother-tongue. They also claimed that the major source of errors are intralingual errors not interlanguage errors. Bailey, Madden, and Krashen (1974) concluded that no significant change occurred in language learning strategies during puberty.

Krashen, Sferlazza, Feldman, and Fathman (1976) claims that when comparing children and adults learning a second language, adults seem to be more dependent on formal environments, which indicate that children are more natural when learning a second language. Generally, adults do not reach the proficiency level of the children that is their learning is less "complete". Recent research indicates that most of the adult language errors are common to all adult learners with different linguistic backgrounds.

The results of the study conducted by Krashen, Sferlazza, Feldman, and Fathman (1976) indicated that child and adult ESL learners found similar aspects of English grammar hard or easy. No matter what their L1 background or linguistic environment, both children and adults learning ESL had similar difficulty orderings (Krashen, Sferlazza, Feldman, and Fathman, 1976). These findings imply in contrast to some of the previous studies that, puberty does not cause a big change in certain aspects of language acquisition. It is possible that adults may have access to younger learners' first and second language acquisition strategies.

Snow (1983), also comparing adults and children, claimed that older learners of second languages are superior to the younger ones. In her study, she tested 52 subjects whose ages change between three and a half and fifty-five, and who are all English subjects, learning Dutch in Netherlands. The tests results on communicative skill-story comprehension and storytelling did not show significant age differences. Moreover, she claims that pronunciation showed the smallest effect between ages.

However, when adults were compared with the teenagers, it was observed that they always scored worse. Snow (1983) claims that this is because adults have less contact with the native speakers, whereas, children had six hours in school and always played with Dutch children who didn't know English.

When testing phonological acquisition, it was found out that children are not superior to adults in pronunciation either, and moreover, the so called "children superiority" is not because they hear sounds better than adults. Snow (1983) agrees that children learn more slowly, but they are able to catch up with adult learners, even surpass them in the long run. She points out the need to make a distinction in second language acquisition. Accordingly, "speed of acquisition and the ultimate level of achievement" (p. 145) are two aspects of SLA that need to be considered separately. Snow (1983) argues that children are better in the ultimate level of achievement, whereas adults are faster in the acquisition process.

According to Snow (1983), neurolinguistic explanations are not adequate to prove the presumption that children are superior in second language learning. Successful language learning is more a result of interaction with native speakers and being unsuccessful is very much related with "social, cultural, or economic barriers to contact with native speakers" (p. 146). She (1983) believes that, adults are better language learners, because they are also better in most of the other learning tasks, when compared with children. This is mostly because of the differences in the cognitive development of children and adults. In addition, adults have more world knowledge and language experience than children.

In another study, Fathman (1975) compares younger children with older children to see if there is a difference in the acquisition rate of English grammar structures among younger and older children, and the order of the acquisition of these structures. The results showed that, the rate of learning changes with age; however, order of acquisition did not 
differ among both groups. However, younger children, preteens, achieved significantly higher ratings in pronunciation. According to Fathman (1975), these differences may be a result of maturational, physiological, or environmental factors. She argues that there might be different critical periods for different aspects of a language. Accordingly, during preteen years children have the ability to discriminate, imitate or interpret sounds better, whereas, after adolescence they become better at understanding rules, memorizing structures and making generalizations.

Since most of the studies on critical period hypothesis are not consistent with each other, Krashen, Long, and Scarcella (1979) brings a different argument. The claim is that, there are three points where these studies become consistent:

1) When the time and exposure is the same adults proceed faster in early syntactic and morphological development;

2) Older children surpass younger children in early stages of morphological and syntactic development, again, when time and exposure are the same;

3) Learning a language in a natural context during childhood results with higher proficiency when compared to those who start learning as an adult.

Krashen , Long, and Scarcella (1979) supports the idea that adults and older children are generally faster in acquiring a second language than children "(older-is-better for rate of acquisition)", but children are superior in the ultimate attainment in second language acquisition "(younger-is-better in the long run)" (p.574). The best predictor of ultimate attainment is the age of arrival in the target language speaking community. It has been found that children become more proficient in second language proficiency, because of their age on the arrival, but after a certain period of time their length of residence do not become a distinguishing factor.

The studies concerning the adult / child differences are usually short term studies, and such studies showed that results are superior to children. The studies comparing older and younger children are again short-term studies which showed that if both groups are exposed to second language for the same period of time and in natural environments older children learn syntax and morphology faster. In addition, in formal environments, when older children are compared with adults, it has seen that older children surpass adults in morphology and syntax in about a year. Other studies comparing children, learning a second language in formal environments showed that those who started school on a later age, caught up with the ones who started earlier. (Krashen, Long, and Scarcella, 1979) This might be because younger learners acquire at a much slower pace, and since older ones have more developed cognitive skills they are able to catch up with them by learning fast.

There are also counter arguments to Krashen's evaluation of the previous CPH studies. In a recent article by Marinova-Todd, Marshall, and Snow (2000) three misconceptions about the relationship of the age of the language learner and the L2 learning is discussed through review of the literature. According to the researchers, first, it is misinterpreted that the ultimate attainment is gained by children since they learn quickly and easily. They argue that, in fact, this was not the case and that literature shows examples of older learners learn more than younger learners when the time is kept constant and actually younger learners learn more slowly and with more effort.

Second, the researchers claim that "neuroscientists have often committed an error of misattribution, assuming that differences in the location of two languages within the brain in speed of processing account for differences in proficiency levels and explain poorer performance of older learners" (p. 14). However, Marinova-Todd, Marshall, and Snow (2000) argue that available data is not adequate to guess the exact nature of brain functioning and language behavior.

Third, they claim that there is a misemphasis of unsuccessful older learners with a native-like proficiency ignored. As a result, Marinova-Todd, Marshall, and Snow (2000) argue that age of the learners is not the only factor that affects L2 proficiency. Social, psychological, educational and similar other factors affect proficiency in addition to the learners' age.

\section{DISCUSSION}

Although the CPH has been investigated by many researchers, the issue of age has not been settled (Scovel, 1988). This is mostly because the issue is more complex so that it involves other factors as well (Nunan, 1999). As can be seen from the previous literature, CPH studies were mostly conducted in ESL environments. However, there is an increase in teaching English in foreign language contexts. Therefore, although results give important insights about adult and child differences in learning a language, contextual, educational, and affective factors are vital to re-consider the results of CPH studies for EFL contexts.

When outlining the pattern of CPH studies Ellis (1985) claims that these studies indicate that age does not have an effect on the route of SLA, that is, the differences in the order of the acquisition is result of other factors. Second, the starting age to learn a language has an effect on the rate of learning so that when the exposure is constant adolescents are better than children and adults. Third, the level of success is affected by the length of exposure and the starting age. The length of exposure contributes to fluency, but the age of learning a SL determines the level of accuracy, especially in pronunciation.

In Europe and in Asia FL teaching has been reduced to primary school and in some countries to kindergarten. If the results of the studies indicate that the major difference that young learners make in learning a language is on 
pronunciation and adolescents are better than adults and young learners in grammar and vocabulary, why are there so many efforts to reduce the age of foreign language learning?

One reason might be related to the fact that exposure to second language plays an important role in the attainment of the language. In contrast to ESL contexts the EFL contexts provide limited exposure to the learners, thus by reducing the age of learning, learners will be exposed to the foreign language longer.

Another difference was seen on the superiority of children on fluency and accurate pronunciation. Similarly, the amount of exposure and the starting age has a great influence to gain native-like pronunciation. This fact also justifies the efforts to reduce the starting age. However, there is another consideration specific to FL contexts, which is related with the language teachers' fluency and accuracy in pronunciation. If this is one of the areas that children are thought to make a difference, they need to be given appropriate modeling of the target language. Yet, the possibility of finding teachers having native-like accents is very limited in the FL environments. The important question that has to be asked here is that whether FL learners have to have a native-like accent. If gaining native-speaker pronunciation is no longer one of the aims of foreign language teaching then we need to re-consider the reasons for learning another language at a younger age.

With the changing needs of the world and the people, the major reason for learning a language become to communicate with other people to keep up with the pace of technology, business, commerce, and mobility. Expecting learners to have a native-like accent would be disregarding the immediate needs of the learners. Fluency and accuracy needs equal emphasis, whereas gaining native-like accent seems secondary when considering the aims of language learning.

Another reason for starting teaching at an early age is a result of people's mobility. For the countries of the EU, for instance, the residents have opportunities to live and work in another country. Not only this requires the competence in the target language but also it requires adapting to the target language community. From this point, the affective explanations of the CPH, as mentioned by Brown (1980) come forth.

Multilingualism and multiculturalism are the recent popular terminologies that we are coming across with frequently. EU's multilingualism strategy is to encourage EU citizens to learn at least two languages in addition to one's native language (EurActiv, 2010). Foreign language learning in such countries is seen as discovering the culture, literature, and the history of the target language community.

Not only in the EU but also all around the world people live and work in countries, which have different native languages than one's own. Because of this reason people learn to adapt to the new country, its culture, its language, and its way of living. As stated earlier this situation may result in culture shock in some cases (Brown, 1993). An early start for learning foreign languages is a facilitative process for children to understand differences and develop a multicultural view point.

When language learning starts at a younger age, it is possible to help children develop positive feelings and attitudes towards other people and cultures having different languages. It creates opportunities to develop acceptance and understanding towards others. Thus, criticisms, incorrect judgments and feelings of superiority would be replaced by recognition and toleration of differences. The result of positive feelings would help children develop positive attitudes towards learning a foreign language. From this perspective it can be argued that teaching FLs to young learners has affective components that help facilitating the language learning process.

In addition to the earlier argument on the effects of contextual factors and purpose of language learning, young learners' cognitive abilities and their characteristics play an important role in FL teaching. The superiority of adolescents can be attributed to their higher cognitive skills than younger learners. The young learner lacks metaawareness, is egocentric, and is not flexible in his/her thinking (Ellis, 1985). Whereas, the adult, after the age 12, moves into Piaget's period of formal operations by developing hypothetical thinking (Dworetzky, 1993). This ability helps him/her to be flexible in thinking and to recognize not only similarities but also differences. The development of metaawareness helps the learner to become more analytical, facilitate efficient learning, and increase the pace of learning (Ellis, 1985), however, at the same time it hinders natural learning.

The difference of children from adolescents and adults in EFL contexts is that they do not have a purpose for learning another language when they can perfectly communicate via their mother tongue. Therefore, they need to be given a reason for learning other languages. A reason for a child might be to enjoy in a classroom activity, relate the content with his/her experience, learning songs, learning about other people and places etc. There could be short term (finishing a puzzle, doing a problem solving activity, learning a song etc.) and long term (making a role-play at the end of the term for the parents, communicating with other children on the internet, understanding the instructions of the computer games etc.) reasons for learning. As they haven't developed abstract thinking, it is difficult for them to imagine how they will use the FL in the far future. For the differences that children have from adults the classroom activities and tasks should be designed according to the characteristics and the cognitive abilities of children.

For language learning the major implication of Piaget's theoretical view is that the child constructs his/her knowledge while working in the environment either with objects or ideas. The child is an active sense-maker, learner and thinker. Yet, these are limited to child's experiences in the world. Thus, children's responses to classroom tasks and activities will be dependent on these experiences (Cameron, 2001). Awareness about children's natural skills facilitates the 
process of designing appropriate tasks and activities to help children have maximum gains from the learning process. According to Halliwell (1992) and Cameron (2001), children are creative, imaginative, they like to have fun even when they are learning, unlike adults they appreciate indirect learning, they like talking and they need scaffolding. By using these natural characteristics of children it is possible to develop appropriate teaching and assessment to increase learning outcomes. In addition, consideration of their cognitive abilities, contextual factors, and reasons for language learning is essential to develop successful language programs.

Although inconsistent, the results of $\mathrm{CPH}$ studies provide great insights for language educators to understand age differences and contextual factors on the outcomes of language teaching. When regarding these studies it is important to realize that FL teaching is not limited to ESL contexts and that not only age but also other factors such as learning context (ESL vs EFL or formal vs informal), affective factors, and reasons for learning languages have influence in success. Thus, language programs developed specifically for young learners need to consider the multiple facets of FL education.

\section{REFERENCES}

[1] Bailey, N. Madden, C., and Krashen, S. D. (1974). Is there a "natural sequence" in adult second language learning. Language Learning, 24, 235-243.

[2] Brown, D. H. (1980). The optimal distance model of second language acquisition. TESOL Quarterly, 14, 157164.

[3] Brown, D. H. (1993). Principles of language learning and teaching. New Jersey: Prentice Hall Regents.

[4] Cameron, (2001). Teaching languages to young learners. UK: Cambridge University Press.

[5] Dworetzky, J. P. (1993). Introduction to child development. USA: West Publishing Company.

[6] Ellis, R. (1985). Understanding second language acquisition. Oxford: Oxford University Press.

[7] EurActiv. EU multilingualism strategy to focus on language learning. Retrieved 6 April 2010, from http://www.euractiv.com/en/culture/eu-multilingualism-strategy-focus-language-learning/article-170364

[8] Fathman, A. (1975). The relationship between age and second language productive ability. Language Learning, 25, $245-246$.

[9] Halliwell, S. (1992). Teaching English in the primary classroom. Spain: Longman.

[10] Johnson, J. S., \& Newport, E. L. (1989). Critical period effects in second language learning: The influence of maturational state on the acquisition of English as a second language. Cognitive Psychology, 21, 60-99.

[11] Krashen, S. D. (1973). Lateralization, language learning, and the critical period: Some new evidence. Language Learning, 23, 63-74.

[12] Krashen, S. D., Sferlazza, V., Feldman, L., \& Fathman, A. (1976). Adult performance on the slope test: More evidence for a natural sequence in adult second language acquisition. Language Learning, 26, 145-151.

[13] Krashen, S. D., Long, M. A., \& Scarcella, R. C. (1979). Age, rate, and eventual attainment in second language acquisition. TESOL Quarterly, 13, 573-583.

[14] Marinova-Todd, S. H., Marshall, D. B., \& Snow, C. E. (2000). Three misconceptions about age and L2 learning. TESOL Quarterly, 34, 9-34.

[15] Nunan, D. (1999). Second language teaching and learning. Boston: Heinle and Heinle Publishers.

[16] Richards, J. C. (1975). Simplification: A strategy in the adult acquisition of a foreign language: An example from Indonesian / Malay. Language Learning, 25, 115-125.

[17] Scovel, T. (1988). A time to speak: A psycholinguistic inquiry into the critical period for human speech. Rowley, Mass.: Newbury House.

[18] Snow, C. E. (1983). Age differences in second language acquisition: Research findings and folk psychology. In Bailey, N. (Ed.), Second Language Acquisition Studies (pp.141-149) Longman \& Peck, \& Newbury House.

Esim Gürsoy is an Assistant Professor in the ELT Department of Faculty of Education at Uludağ University, Bursa-Turkey. She received her M.ED from the Teacher Training Department at Ohio University, USA in 1998 and her Ph.D from the ELT department at Anadolu University, Turkey in 2004. She also received a TESL/TEFL certificate from the Linguistic Department at Ohio University in 1997. She is currently offering courses at the graduate and undergraduate level at Uludağ University. Her research interests include foreign language teaching to young learners, technology use in teaching foreign languages, teacher training, and global issues in ELT. 